\title{
Why Do Falls and Lower Limb Fractures Occur More Frequently in the Diabetic Patient and How Can They Be Prevented?
}

\author{
David S. H. Bell • Edison Goncalves
}

Received: June 3, 2020 / Published online: July 10, 2020

(C) The Author(s) 2020

\section{ABSTRACT}

Due to primarily sarcopenia and hypoglycemia but also neuropathy, hypotension, analgesics and polypharmacy, there is an increased incidence of falls and hip fractures in both the type 1 and type 2 diabetic patient. Utilization of insulin, hypotensive drugs, analgesics and perhaps canagliflozin further increases the risk. Thiazolidinedione use may increase the risk of osteoporosis and fracture. Prolonged hyperglycemia resulting in cross-linking of collagen and advanced glycosylation end products alter the microarchitecture and increase bone fragility. Higher serum vitamin D levels seem to decrease the incidence of both falls and fractures. Following a hip fracture, mortality in the diabetic patient is increased largely because of cardiovascular events and pneumonia. Prevention of sarcopenia includes dietary therapy, vitamin $\mathrm{D}$ and testosterone replacement when appropriate.

Digital Features To view digital features for this article go to: https://doi.org/10.6084/m9.figshare.12587939.

\section{S. H. Bell $(\bowtie) \cdot$ E. Goncalves}

Southside Endocrinology and Diabetes and Thyroid

Associates, Birmingham, AL, USA

e-mail: dshbell@yahoo.com
Keywords: Aging; Diabetes; Falls; Fractures; Hypoglycemia; Neuropathy; Osteoporosis; Polypharmacy; Sarcopenia

\section{Key Summary Points}

There is an increased incidence of falls and fractures in patients with type 1 and 2 diabetes.

Insulin, hypotensive drugs, analgesics and canagliflozin further increase the risk.

Thiazolidinedione use may increase the risk of osteoporosis and fracture.

After a fall, mortality in the diabetic patient is increased because of cardiovascular events and pneumonia.

We carried out this review after observing how frequently patients with diabetes sustain falls and fractures.

There is an unmet need to find ways to prevent falls and fractures in this population. 


\section{INTRODUCTION}

A fall can be defined as an event that results in inadvertently coming to rest on the ground or floor [1]. Over the age of 65 years, 59\% of patients report at least one fall per year and over age 65 almost all fractures of the hip are due to falls [2].

The first phase in a fall is a trip or slip, which is more frequent because of weakness of the distal musculature. At this point, the fall can be corrected through activity of the proximal lower limb muscles but if there is weakness of these muscles the fall continues so that balance cannot be regained [3, 4]. Furthermore, the ability to abort a fall may also be negated by upper limb weakness resulting in an inability to grasp an object to regain balance. Following a fall, hip fracture is more common in the presence of osteoporosis and/or poor bone quality.

In general, hip is the most common fracture in the elderly population, and it is associated with an increased mortality and poor functional recovery [5-7]. This severe medical and socioeconomical burden is even greater in the diabetic patient [8].

At least 400 factors are associated with falls with the most important being a previous fall. However, other significant risk factors are hypertension, diabetes, pain and polypharmacy $[9,10]$. This article is based on previously conducted studies and does not contain any studies with human participants or animals performed by any of the authors.

\section{DIABETIC NEUROPATHY, FALLS AND FRACTURES IN THE PATIENT WITH DIABETES}

At any age, the incidence of falls and fractures is increased in the patient with diabetes. It has been widely believed that this is largely due to the presence of distal symmetric and autonomic neuropathy causing decreases in sensory perception and balance [11]. Fifty percent of people with type 2 diabetes have neuropathy, which leads to a decrease in life expectancy as well as quality of life. Furthermore, sensory defects in the feet are associated with increased postural motion and slower gait. This detrimental effect on gait leads to a disruption in the body's sensorimotor system, another important mechanism of falls [12-14]. However, the association of diabetic neuropathy and falls may be even greater in those with decreased proprioception as assessed by a defect in joint position sense. In a cross-sectional study of patients with diabetic neuropathy diagnosed by clinical assessment and electrophysiologic studies, $85 \%$ had decreased vibratory sensibility, $70 \%$ absent ankle reflex and only $39.6 \%$ had decreased joint position defined as two or more errors in a trial of ten toe positions; however, the study lacks data on the severity of the distal sensory neuropathy [15]. The decreased joint position sense indicates sensory deterioration and frequently occurs in conjunction with muscle atrophy. Diabetic peripheral neuropathy appears to be an independent risk factor and correlates with sarcopenia, which becomes more obvious with the aggravation of neurologic symptoms [16]. This suggests that the association of diabetic distal symmetrical polyneuropathy with falls and fractures could be due to neuropathy and/ or sarcopenia. In addition, patients who have symptomatic diabetic neuropathy are more likely to be taking medications with a sedative effect, which will further augment their risk of a fall [17].

\section{HYPOGLYCEMIA, HYPOTENSION AND POLYPHARMACY CAUSING FALLS}

In a meta-analysis of six studies using a random effects model and including 14,685 subjects, there was a $64 \%$ (95\% CI 1.27-2.11) increase in hip fractures among those with diabetes. However, if insulin was being utilized there was a 94\% (95\% CI 1.42-2.63) increase in risk compared to $27 \%$ (95\% CI 1.06-1.52) in non-insulin users [18]. In another meta-analysis diabetes was associated with an increased risk of hip fractures (RR 2.07; 95\% CI 1.83-2.33), and subgroup analysis indicated that the excess risk was more pronounced in type 1 diabetes (RR 5.76; 95\% CI 3.66-9.07) than that in type 2 diabetes 
(RR 1.34; 95\% CI 1.19-1.51) [19, 20]. These data were confirmed by a study that showed that while the relative risk of any fracture was mildly increased (RR 1.295 CI 1.01-1.15), fracture of the hip was increased 2.8 fold (CI 95\% 1.2-1.66) in type 2 male diabetic subjects and 2.1 fold (95\% CI 1.6-2.7) in female type 2 diabetic subjects [21]. From these data we must assume that use of insulin is associated with increased risk of falls. This could be due to hypoglycemia leading to an acute decrease in coordination, but this association could be due to other mechanisms. In the Women's Health and Aging Study insulin use was considered a marker of diabetes severity. However, after adjustment for several diabetes-related comorbidities, duration of disease (a variable strongly correlated with insulin therapy) and time-dependent measures of physical function did not modify the association between insulin use and risk of falling. These findings suggest that other mechanisms underlie the association between insulin therapy and risk of falling. Since insulin is the most important risk factor for hypoglycemia, it is plausible, although unproven, that it might explain the excess risk of falls [22]. In addition, falls associated with hypoglycemia have a $70 \%$ higher risk of leading to a fracture and are more likely to result in a visit to the emergency room, hospitalization and long-term care placement $[23,24]$.

Sulfonylureas, despite being associated with a higher risk of hypoglycemia, have not been shown to increase the frequency of falls and fractures. Likewise, metformin, DPP-4 inhibitors and GLP-1 receptor agonists, which do not induce hypoglycemia, have not been associated with fractures. Only one of the SGLT-2 inhibitors (canagliflozin) has been shown to increase the risk of fracture in a single study, even though it does not cause a decrease in bone mineral density other than in the total hip area, which can be expected to occur with weight loss [25]. In the CANVAS study there was an increase in fractures, often of the upper limbs, which was presumably due to hypotension and falls [26]. However, in the CANVAS-R trial the risk of fracture was not increased [27]. The difference between the CANVAS and CANVAS-R trials is that in the former hypotensive agents such as diuretics and inhibitors of the renin-angiotensin-aldosterone (RAA) system could not be discontinued prior to the initiation of canagliflozin therapy, whereas in the later this was permitted, which would explain the increase in falls and fractures in the CANVAS study. In addition to hypoglycemia, patients with diabetes and autonomic neuropathy, as well as those on diuretics and other anti-hypertensive drugs, are at risk of a fall due to orthostasis. Polypharmacy with certain analgesics, muscle relaxants and tranquilizers further increases the fall risk $[28,29]$.

\section{SARCOPENIA}

Sarcopenia, the frequency of which is associated with hypogonadism, aging and diabetes, results in decreased muscle mass, strength and function. In a Chinese population the prevalence of sarcopenia and pre-sarcopenia in patients with diabetes was significantly increased by $14 \%$ compared to controls. After multivariate logistic regression analyses (adjusting by age, gender, anti-diabetic medication, caloric and protein intake, physical activity and visceral fat) elderly patients with T2DM exhibited a significant 37\% increase in risk of sarcopenia and 73\% increase in pre-sarcopenia compared to non-diabetic individuals [30].

Sarcopenia can be defined as a progressive skeletal muscle disorder characterized by decreased muscle quantity and strength accompanied by decreased physical muscle performance [31]. Sarcopenia is caused by degeneration at the neuromuscular junction and loss of motor units. It is also associated with increased catabolism of muscle, insulin resistance, decreased IGF-1, anabolic resistance, inflammation and oxidative stress as well as clinically with anorexia and nutritional deficiencies [32, 33]. Sarcopenia is also associated with an increased ratio of slow-to-fast twitching muscle units, which adds to the loss of power, thus decreasing the ability to extend force quickly to regain balance [34]. Clinically, decreased hand strength is not only the best marker for sarcopenia but also a much better determination of the risk of a fall (since it may 
also evaluate motor neuropathy) $[35,36]$. Perhaps regular measurements of hand strength using an inexpensive device may be an asset in the risk assessment of falls and fractures, particularly of the hips, in patients with diabetes.

\section{THERAPY OF SARCOPENIA IN THE DIABETIC PATIENT}

Treatment of sarcopenia involves dietary therapy and exercise. Leucine supplementation has grown in popularity due to the discovery of its anabolic effects on cell signaling and protein synthesis in muscle [37]. Undernutrition is present in as many as $10 \%$ of communitydwelling and as much as $65 \%$ of institutionalized patients. There is strong, but not conclusive, evidence that correcting low vitamin D levels not only improves muscle strength but also decreases the frequency of falls as shown in a meta-analysis of double-blind randomized controlled trials. Eight studies that contained 2426 subjects showed that the daily intake of 700-1000 IU of vitamin D reduced the risk of falls by $19 \%$ (95\% CI 0.71-0.92) whereas lower daily intake (200-600 IU) was not effective [38-40].

A cross-sectional study of the National Health Survey III, which included 13,432 subjects, showed an association between high $25-\mathrm{OH}$ vitamin D levels $(22.5-94 \mathrm{nmol} / \mathrm{l})$ and high bone mineral density. However, in the largest placebo-controlled RCT done so far, daily vitamin D3 supplementation for 2 years did not have a significant effect on bone mineral density (BMD) of the spine and hip, or structure and strength measures at the radius and tibia, in a population of older adults in the US not specifically selected for vitamin D insufficiency [41, 42].

In addition to its action on bone, vitamin $\mathrm{D}$ also has an effect on muscle. For example, in the vitamin $\mathrm{D}$ receptor knockout mouse there is atrophy of muscle as well as reduced function [43]. Vitamin D levels $<40 \mathrm{ng} / \mathrm{ml}$ are associated with myopathy and decreased function of fasttwitching type 2 muscle fibers [44, 45]. In institutionalized subjects a normal $25-\mathrm{OH}$ vitamin D level is associated with improved psychomotor function, muscle performance and strength, and a slower decline in muscle function has been shown as well as less sarcopenia and falls [46-50]. Nutritional intervention involving protein supplementation (but not other dietary interventions) especially in conjunction with exercise produces consistent improvements in lower body muscle strength but has less consistent effects on hand grip or walking speed [51]. Therefore, based on these data, largely due to muscle dysfunction, and less due to changes in BMD, there is a decrease in falls and fractures in subjects with a vitamin $\mathrm{D}$ intake > $700 \mathrm{IU}$ daily and $25-\mathrm{OH}$ vitamin $\mathrm{D}$ levels $>40 \mathrm{ng} / \mathrm{ml}$.

In men with hypogonadism, defined as a serum testosterone level $<280 \mathrm{ng} / \mathrm{dl}$, replacement to achieve age appropriate normal levels has been shown to improve muscle mass and strength [52].

However, it is unclear whether testosterone improves mobility or reduces the risk of falls in older men. In 2004 the Institute of Medicine concluded that there was insufficient evidence that testosterone treatment of older men with low testosterone was beneficial and recommended a large trial to evaluate its benefits and possible risks [53]. The Testosterone Trials (TTrials) evaluated testosterone treatment in older men with age-related decline in testosterone levels and one or more symptoms or signs of testosterone deficiency [54]. In the secondary analyses of the Testosterone Trials, testosterone administration in older men with mobility limitation ( $42 \%$ with diabetes) consistently improved self-reported measures of physical function and modestly improved mobility but did not affect fall frequency. The treatment effect on mobility measures was small and seemed to be related to baseline gait speed and self-reported mobility limitation. The authors concluded that testosterone therapy should probably not be started specifically to improve physical function, although men who are treated with testosterone for other reasons could have some improvement in physical function [54]. 


\section{OSTEOPOROSIS AND BONE FRAGILITY}

Patients with both type 1 and type 2 diabetes have an increased risk of fractures, which is underestimated by measurements of bone mineral density $[55,56]$. Those with poor glycemic control and who have had diabetes for a long time, those with microvascular complications and those who are utilizing insulin are at the highest risk of both bone fragility and fracture.

In type 1 diabetes bone mineral density (BMD) is often low. However, normal or even elevated bone mineral density is seen in type 2 diabetes patients, probably due to increased estradiol levels occurring because of increased aromatization of androgens, which in turn is due to an increase in adipose mass. In both type 1 and type 2 diabetes bone turnover is also decreased so that the microstructure of bone is altered particularly when the microvascular complications (retinopathy and nephropathy) are present. A possible explanation for increased bone fragility is that cross-linking of collagen due to the prolonged hyperglycemia resulting in formation of advanced glycosylated end products (AGE) leads to alteration of bone microstructure and biomechanical properties [57, 58]. Thiazolidinedione use can lead to osteoporosis because of an increase in the formation of adipocytes at the expense of osteocytes, leading not only to osteoporosis but also to an increase in marrow adiposity and increased adipocytokine levels, which further increase local inflammation contributing to bone fragility $[59,60]$. Another factor that may play a role in the increase in bone fragility associated with diabetes is increased osteocyte dysregulation [61].

\section{OUTCOMES OF HIP FRACTURE IN THE DIABETIC PATIENT}

Mortality is increased following a fall accompanied by a hip fracture in the diabetic patient. A population-based cohort study of 55,891 type 2 diabetic subjects with hip fractures was compared with 103,093 non-diabetic subjects > 80 years old. With diabetes, mortality was 48.8 versus 33.8 per 1000 person years in the nondiabetic subjects. Therefore, diabetic subjects had a $50 \%$ increase in mortality over the following 5 years. These data are based on clinical records, and there is lack of validation concerning whether individual fractures are due to fragility or not [62]. In a population-based prospective cohort study from Catalonia, Spain, patients with type 2 diabetes had, compared to patients without diabetes, a post-hip fracture increase in mortality of 28\% (CI 95\% 1.02-1.60) in men and 57\% (95\% CI 1.31-1.82) in women [63]. The increase in the mortality following hip fracture in the diabetic subject is assumed to be due to increases in the incidences of cardiovascular death and pneumonia [64].

\section{CONCLUSION}

There is an increased risk of falls due to sarcopenia, hypoglycemia, hypotension, analgesics and distal symmetrical polyneuropathy in the diabetic patient. Furthermore, this increased fracture risk rises even in the absence of decreased bone mineral density because of increased bone fragility likely due to glycosylation of collagen and inflammation altering bone architecture. Vitamin D intake and higher $25-\mathrm{OH}$ vitamin $\mathrm{D}$ levels may be protective in both avoiding falls and decreasing fractures. Therapy with insulin, analgesics, thiazolidinediones and perhaps canagliflozin increases the risk of falls and fractures in the diabetic patient. The mortality following a hip fracture is increased in the diabetic patient because of increased cardiac events and pneumonia.

\section{ACKNOWLEDGEMENTS}

Funding. No funding or sponsorship was received for this study or publication of this article.

Authorship. All named authors meet the International Committee of Medical Journal Editors (ICMJE) criteria for authorship for this article, take responsibility for the integrity of 
the work as a whole and have given their approval for this version to be published.

Authorship Contributions. Both authors contributed equally to this paper.

Disclosures. David S. H. Bell serves as a consultant for and is a member of the speaker's bureau of Mannkind Corporation and is a member of the speaker's bureau of Novo-Nordisk, AstraZeneca and Janssen. David S. H. Bell is also a member of the journal's Editorial Board. Edison Goncalves is a member of the speaker's bureau of Janssen and Novo-Nordisk.

Compliance with Ethics Guidelines. This article is based on previously conducted studies and does not contain any studies with human participants or animals performed by any of the authors.

Open Access. This article is licensed under a Creative Commons Attribution-NonCommercial 4.0 International License, which permits any non-commercial use, sharing, adaptation, distribution and reproduction in any medium or format, as long as you give appropriate credit to the original author(s) and the source, provide a link to the Creative Commons licence, and indicate if changes were made. The images or other third party material in this article are included in the article's Creative Commons licence, unless indicated otherwise in a credit line to the material. If material is not included in the article's Creative Commons licence and your intended use is not permitted by statutory regulation or exceeds the permitted use, you will need to obtain permission directly from the copyright holder. To view a copy of this licence, visit http://creativecommons.org/licenses/by$\mathrm{nc} / 4.0 /$.

\section{REFERENCES}

1. Zecevic AA, Salmoni AW, Speechley M, Vandervoort AA. Defining a fall and reasons for falling: comparisons among the views of seniors, health care providers, and the research literature. Gerontologist. 2006;46(3):367-76.
2. Rubenstein LZ, Josephson KR. Falls and their prevention in elderly people: what does the evidence show? Med Clin N Am. 2006;90(5):807-24.

3. Crenshaw JR, Bernhardt KA, Achenbach SJ, et al. The circumstances, orientations, and impact locations of falls in community-dwelling older women. Arch Gerontol Geriatr. 2017;73:240-7.

4. Horlings CG, van Engelen BG, Allum JH, Bloem BR. A weak balance: the contribution of muscle weakness to postural instability and falls. Nat Clin Pract Neurol. 2008;4(9):504-15.

5. Kanis JA, Oden A, McCloskey EV, et al. A systematic review of hip fracture incidence and probability of fracture worldwide. Osteoporos Int. 2012;23(9): 2239-56.

6. Gulcelik NE, Bayraktar M, Caglar O, Alpaslan M, Karakaya J. Mortality after hip fracture in diabetic patients. Exp Clin Endocrinol Diabetes. 2011;119(7):414-8.

7. Bertram M, Norman R, Kemp L, Vos T. Review of the long-term disability associated with hip fractures. Inj Prev. 2011;17(6):365-70.

8. Lee YK, Koo KH. Osteoporotic hip fracture in the elderly patients: physicians' views. J Korean Med Sci. 2013;28(7):976-7.

9. Close JC, Lord SL, Menz HB, Sherrington C. What is the role of falls? Best Pract Res Clin Rheumatol. $2005 ; 19(6): 913-35$.

10. Boyd R, Stevens JA. Falls and fear of falling: burden, beliefs and behaviours. Age Ageing. 2009;38(4):423-8.

11. Vinik AI, Camacho P, Reddy $S$, et al. Aging, diabetes, and falls. Endocr Pract. 2017;23(9):1117-39.

12. Alam U, Riley DR, Jugdey RS, et al. Diabetic neuropathy and gait: a review. Diabetes Ther. 2017;8(6):1253-64.

13. Strotmeyer ES, de Rekeneire N, Schwartz AV, et al. The relationship of reduced peripheral nerve function and diabetes with physical performance in older white and black adults: the health, aging, and body composition (Health ABC) study. Diabetes Care. 2008;31(9):1767-72.

14. Herriott MT, Colberg SR, Parson HK, Nunnold T, Vinik AI. Effects of 8 weeks of flexibility and resistance training in older adults with type 2 diabetes. Diabetes Care. 2004;27(12):2988-9.

15. Prabhakar AT, Suresh T, Kurian DS, et al. Timed vibration sense and joint position sense testing in the diagnosis of distal sensory polyneuropathy. J Neurosci Rural Pract. 2019;10(2):273-7. 
16. Yang Q, Zhang Y, Zeng Q, et al. Correlation between diabetic peripheral neuropathy and sarcopenia in patients with type 2 diabetes mellitus and diabetic foot disease: a cross-sectional study. Diabetes Metab Syndr Obes. 2020;13:377-86.

17. Sri-On J, Tirrell GP, Bean JF, Lipsitz LA, Liu SW. Revisit, subsequent hospitalization, recurrent fall, and death within 6 months after a fall among elderly emergency department patients. Ann Emerg Med. 2017;70(4):516 e512-21 e512.

18. Yang Y, Hu X, Zhang Q, Zou R. Diabetes mellitus and risk of falls in older adults: a systematic review and meta-analysis. Age Ageing. 2016;45(6):761-7.

19. Thong EP, Herath M, Weber DR, et al. Fracture risk in young and middle-aged adults with type 1 diabetes mellitus: a systematic review and meta-analysis. Clin Endocrinol (Oxf). 2018;89(3):314-23.

20. Fan Y, Wei F, Lang Y, Liu Y. Diabetes mellitus and risk of hip fractures: a meta-analysis. Osteoporos Int. 2016;27(1):219-28.

21. Janghorbani M, Van Dam RM, Willett WC, Hu FB. Systematic review of type 1 and type 2 diabetes mellitus and risk of fracture. Am J Epidemiol. 2007;166(5):495-505.

22. Volpato S, Leveille SG, Blaum C, Fried LP, Guralnik JM. Risk factors for falls in older disabled women with diabetes: the women's health and aging study. J Gerontol A Biol Sci Med Sci. 2005;60(12):1539-45.

23. Johnston SS, Conner C, Aagren M, Ruiz K, Bouchard J. Association between hypoglycaemic events and fall-related fractures in Medicare-covered patients with type 2 diabetes. Diabetes Obes Metab. 2012;14(7):634-43.

24. Zhao Y, Kachroo S, Kawabata H, et al. Association between hypoglycemia and fall-related fractures and health care utilization in older veterans with type 2 diabetes. Endocr Pract. 2016;22(2):196-204.

25. Bilezikian JP, Watts NB, Usiskin K, et al. Evaluation of bone mineral density and bone biomarkers in patients with type 2 diabetes treated with canagliflozin. J Clin Endocrinol Metab. 2016;101(1):44-51.

26. Zhou Z, Jardine M, Perkovic V, et al. Canagliflozin and fracture risk in individuals with type 2 diabetes: results from the CANVAS Program. Diabetologia. 2019;62(10):1854-67.

27. Neal B, Perkovic V, Matthews DR, et al. Rationale, design and baseline characteristics of the CANagliflozin cardioVascular Assessment Study-Renal (CANVAS-R): a randomized, placebo-controlled trial. Diabetes Obes Metab. 2017;19(3):387-93.
28. Dhalwani NN, Fahami R, Sathanapally H, Seidu S, Davies MJ, Khunti K. Association between polypharmacy and falls in older adults: a longitudinal study from England. BMJ Open. 2017;7(10): e016358.

29. Janus SIM, Reinders GH, van Manen JG, Zuidema SU, Ijzerman MJ. Psychotropic drug-related fall incidents in nursing home residents living in the Eastern Part of The Netherlands. Drugs R D. 2017;17(2):321-8.

30. Wang T, Feng X, Zhou J, et al. Type 2 diabetes mellitus is associated with increased risks of sarcopenia and pre-sarcopenia in Chinese elderly. Sci Rep. 2016;6:38937.

31. Cruz-Jentoft AJ, Bahat G, Bauer J, et al. Sarcopenia: revised European consensus on definition and diagnosis. Age Ageing. 2019;48(1):16-311.

32. Benichou O, Lord SR. Rationale for strengthening muscle to prevent falls and fractures: a review of the evidence. Calcif Tissue Int. 2016;98(6):531-45.

33. Schneider SM, Al-Jaouni R, Pivot X, Braulio VB, Rampal P, Hebuterne X. Lack of adaptation to severe malnutrition in elderly patients. Clin Nutr. 2002;21(6):499-504.

34. Lang T, Streeper T, Cawthon P, Baldwin K, Taaffe DR, Harris TB. Sarcopenia: etiology, clinical consequences, intervention, and assessment. Osteoporos Int. 2010;21(4):543-59.

35. Looker AC, Wang CY. Prevalence of reduced muscle strength in older US adults: United States, 2011-2012. NCHS Data Brief. 2015;179:1-8.

36. Davies CW, Jones DM, Shearer JR. Hand grip-a simple test for morbidity after fracture of the neck of femur. J R Soc Med. 1984;77(10):833-6.

37. Tessier AJ, Chevalier S. An update on protein, leucine, omega- 3 fatty acids, and vitamin $\mathrm{D}$ in the prevention and treatment of sarcopenia and functional decline. Nutrients. 2018;10(8):321-8.

38. Bischoff-Ferrari HA, Dawson-Hughes B, Staehelin $\mathrm{HB}$, et al. Fall prevention with supplemental and active forms of vitamin D: a meta-analysis of randomised controlled trials. BMJ. 2009;339:b3692.

39. Bischoff-Ferrari H. Vitamin D: what is an adequate vitamin D level and how much supplementation is necessary? Best Pract Res Clin Rheumatol. 2009;23(6):789-95.

40. Tang BM, Eslick GD, Nowson C, Smith C, Bensoussan A. Use of calcium or calcium in combination with vitamin D supplementation to prevent fractures and bone loss in people aged 50 years and 
older: a meta-analysis. Lancet. 2007;370(9588): 657-66.

41. Bischoff-Ferrari HA, Dietrich T, Orav EJ, DawsonHughes B. Positive association between 25-hydroxy vitamin $\mathrm{D}$ levels and bone mineral density: a population-based study of younger and older adults. Am J Med. 2004;116(9):634-9.

42. LeBoff MS, Chou SH, Murata EM, et al. Effects of supplemental vitamin D on bone health outcomes in women and men in the VITamin D and OmegA-3 TriaL (VITAL). J Bone Miner Res. 2020;35(5): 883-93.

43. Endo I, Inoue D, Mitsui T, et al. Deletion of vitamin $\mathrm{D}$ receptor gene in mice results in abnormal skeletal muscle development with deregulated expression of myoregulatory transcription factors. Endocrinology. 2003;144(12):5138-44.

44. Bischoff-Ferrari HA, Dawson-Hughes B, Baron JA, et al. Calcium intake and hip fracture risk in men and women: a meta-analysis of prospective cohort studies and randomized controlled trials. Am J Clin Nutr. 2007;86(6):1780-90.

45. Simpson RU, Thomas GA, Arnold AJ. Identification of 1,25-dihydroxyvitamin D3 receptors and activities in muscle. J Biol Chem. 1985;260(15):8882-91.

46. Dhesi JK, Bearne LM, Moniz C, et al. Neuromuscular and psychomotor function in elderly subjects who fall and the relationship with vitamin $\mathrm{D}$ status. J Bone Miner Res. 2002;17(5):891-7.

47. Wicherts IS, van Schoor NM, Boeke AJ, et al. Vitamin D status predicts physical performance and its decline in older persons. J Clin Endocrinol Metab. 2007;92(6):2058-65.

48. Kaiser MJ, Bauer JM, Ramsch C, et al. Frequency of malnutrition in older adults: a multinational perspective using the mini nutritional assessment. J Am Geriatr Soc. 2010;58(9):1734-8.

49. Chien MH, Guo HR. Nutritional status and falls in community-dwelling older people: a longitudinal study of a population-based random sample. PLoS ONE. 2014;9(3):e91044.

50. Cruz-Jentoft AJ, Kiesswetter E, Drey M, Sieber CC. Nutrition, frailty, and sarcopenia. Aging Clin Exp Res. 2017;29(1):43-8.

51. Anton SD, Hida A, Mankowski R, et al. Nutrition and exercise in sarcopenia. Curr Protein Pept Sci. 2018;19(7):649-67.

52. Saad F, Rohrig G, von Haehling S, Traish A. Testosterone deficiency and testosterone treatment in older men. Gerontology. 2017;63(2):144-56.
53. Liverman CT, Blazer DG, National Research Council (U.S.). Committee on Assessing the Need for Clinical Trials of Testosterone Replacement Therapy. Testosterone and aging: clinical research directions. Washington, D.C.: National Academies Press; 2004.

54. Bhasin S, Ellenberg SS, Storer TW, et al. Effect of testosterone replacement on measures of mobility in older men with mobility limitation and low testosterone concentrations: secondary analyses of the Testosterone Trials. Lancet Diabetes Endocrinol. 2018;6(11):879-90.

55. Giangregorio LM, Leslie WD, Lix LM, et al. FRAX underestimates fracture risk in patients with diabetes. J Bone Miner Res. 2012;27(2):301-8.

56. Schwartz AV, Vittinghoff E, Bauer DC, et al. Association of BMD and FRAX score with risk of fracture in older adults with type 2 diabetes. JAMA. 2011;305(21):2184-92.

57. Karim L, Bouxsein ML. Effect of type 2 diabetesrelated non-enzymatic glycation on bone biomechanical properties. Bone. 2016;82:21-7.

58. Furst JR, Bandeira LC, Fan WW, et al. Advanced glycation endproducts and bone material strength in type 2 diabetes. J Clin Endocrinol Metab. 2016;101(6):2502-10.

59. Napoli N, Chandran M, Pierroz DD, et al. Mechanisms of diabetes mellitus-induced bone fragility. Nat Rev Endocrinol. 2017;13(4):208-19.

60. Pavlova V, Filipova E, Uzunova K, Kalinov K, Vekov T. Pioglitazone therapy and fractures: systematic review and meta-analysis. Endocr Metab Immune Disord Drug Targets. 2018;18(5):502-7.

61. Murray CE, Coleman CM. Impact of diabetes mellitus on bone health. Int J Mol Sci. 2019;20(19): 4873.

62. Tebe C, Martinez-Laguna D, Moreno V, et al. Differential mortality and the excess rates of hip fracture associated with type 2 diabetes: accounting for competing risks in fracture prediction matters. J Bone Miner Res. 2018;33(8):1417-21.

63. Tebe C, Martinez-Laguna D, Carbonell-Abella C, et al. The association between type 2 diabetes mellitus, hip fracture, and post-hip fracture mortality: a multi-state cohort analysis. Osteoporos Int. 2019;30(12):2407-15.

64. von Friesendorff M, McGuigan FE, Wizert A, et al. Hip fracture, mortality risk, and cause of death over two decades. Osteoporos Int. 2016;27(10):2945-53. 